This item was submitted to Loughborough's Research Repository by the author.

Items in Figshare are protected by copyright, with all rights reserved, unless otherwise indicated.

\title{
A tunable amorphous p-type ternary oxide system: the highly mismatched alloy of copper tin oxide
}

PLEASE CITE THE PUBLISHED VERSION

http://dx.doi.org/10.1063/1.4929752

\section{PUBLISHER}

(C) American Institute of Physics (AIP)

\section{VERSION}

VoR (Version of Record)

\section{PUBLISHER STATEMENT}

This work is made available according to the conditions of the Creative Commons Attribution-NonCommercialNoDerivatives 4.0 International (CC BY-NC-ND 4.0) licence. Full details of this licence are available at: https://creativecommons.org/licenses/by-nc-nd/4.0/

\section{LICENCE}

CC BY-NC-ND 4.0

\section{REPOSITORY RECORD}

Isherwood, Patrick J.M., K.T. Butler, A. Walsh, and Michael Walls. 2019. "A Tunable Amorphous P-type Ternary Oxide System: The Highly Mismatched Alloy of Copper Tin Oxide”. figshare. https://hdl.handle.net/2134/19060. 


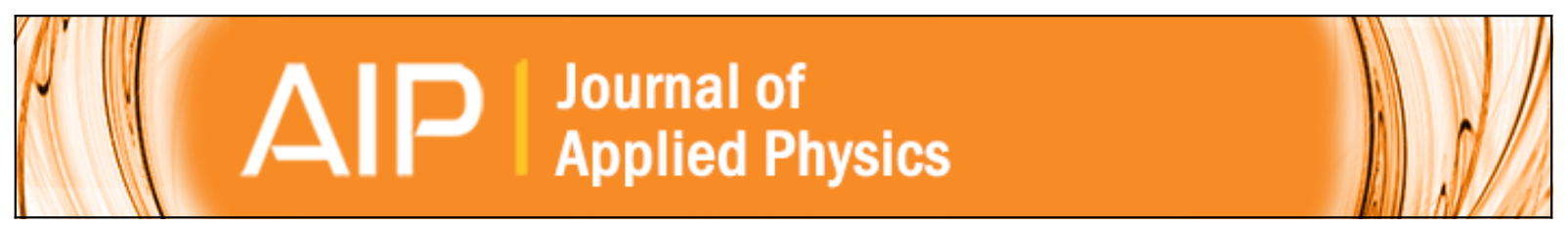

\section{A tunable amorphous p-type ternary oxide system: The highly mismatched alloy of copper tin oxide}

Patrick J. M. Isherwood, Keith T. Butler, Aron Walsh, and John M. Walls

Citation: Journal of Applied Physics 118, 105702 (2015); doi: 10.1063/1.4929752

View online: http://dx.doi.org/10.1063/1.4929752

View Table of Contents: http://scitation.aip.org/content/aip/journal/jap/118/10?ver=pdfcov

Published by the AIP Publishing

\section{Articles you may be interested in}

Atomic layer deposition of tin oxide and zinc tin oxide using tetraethyltin and ozone

J. Vac. Sci. Technol. A 33, 021517 (2015); 10.1116/1.4907562

Enhancement of p-type mobility in tin monoxide by native defects

Appl. Phys. Lett. 102, 212105 (2013); 10.1063/1.4808382

Highly conductive p-type amorphous oxides from low-temperature solution processing

Appl. Phys. Lett. 101, 132104 (2012); 10.1063/1.4754608

Electrical properties and stability of p-type $\mathrm{ZnO}$ film enhanced by alloying with $\mathrm{S}$ and heavy doping of $\mathrm{Cu}$

Appl. Phys. Lett. 97, 142101 (2010); 10.1063/1.3496038

Effect of an applied voltage during annealing on the resistivity and transparency of the amorphous tin oxide films J. Vac. Sci. Technol. A 21, 1923 (2003); 10.1116/1.1619415

\section{AIP $\left.\right|_{\text {APL Photonics }}$}

APL Photonics is pleased to announce Benjamin Eggleton as its Editor-in-Chief

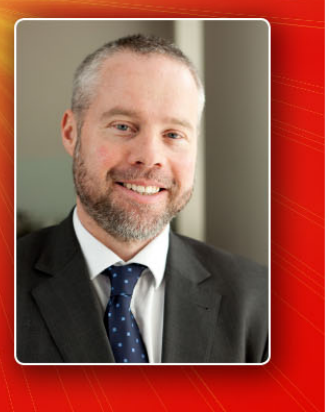




\title{
A tunable amorphous p-type ternary oxide system: The highly mismatched alloy of copper tin oxide
}

\author{
Patrick J. M. Isherwood, ${ }^{1, \text { a) }}$ Keith T. Butler, ${ }^{2}$ Aron Walsh, ${ }^{2}$ and John M. Walls ${ }^{1}$ \\ ${ }^{1}$ CREST, School of Electronic, Electrical and Systems Engineering, Loughborough University, Loughborough, \\ Leicestershire LE11 3TU, United Kingdom \\ ${ }^{2}$ Centre for Sustainable Technologies and Department of Chemistry, University of Bath, Claverton Down, \\ Bath BA2 7AY, United Kingdom
}

(Received 30 May 2015; accepted 17 August 2015; published online 9 September 2015)

\begin{abstract}
The approach of combining two mismatched materials to form an amorphous alloy was used to synthesise ternary oxides of $\mathrm{CuO}$ and $\mathrm{SnO}_{2}$. These materials were analysed across a range of compositions, and the electronic structure was modelled using density functional theory. In contrast to the gradual reduction in optical band gap, the films show a sharp reduction in both transparency and electrical resistivity with copper contents greater than $50 \%$. Simulations indicate that this change is caused by a transition from a dominant $\mathrm{Sn} 5 \mathrm{~s}$ to $\mathrm{Cu} 3 \mathrm{~d}$ contribution to the upper valence band. A corresponding decrease in energetic disorder results in increased charge percolation pathways: a "compositional mobility edge." Contributions from $\mathrm{Cu}(\mathrm{II})$ sub band-gap states are responsible for the reduction in optical transparency. (C) 2015 AIP Publishing LLC.
\end{abstract}

[http://dx.doi.org/10.1063/1.4929752]

\section{INTRODUCTION}

Transparent amorphous oxide semiconductors (TAOS) have opened up a huge array of possibilities for transparent, flexible opto-electronics devices. ${ }^{1-4}$ These amorphous materials possess the fundamental advantages of low-cost synthesis and smooth, uniform grain-boundary free films, enabling production in large-scale roll-to-roll processes. In order to fully exploit the technological avenues opened up by n-type TAOS, it is necessary to produce p-type counterparts. p-type TAOS would provide access to the multitude of semiconductor heterojunction technologies that have revolutionised science and technology in the latter part of the 20th century, but in low-cost, easily manufactured and highly versatile forms.

The task of developing p-type amorphous oxides faces two fundamental challenges: (i) materials capable of stabilising electron holes and (ii) ensuring sufficiently high hole mobility. The former relies on ensuring sufficiently low binding energy valence band maxima (VBM), whilst the latter in part depends on the orbital character of the valence band itself. The search for effective TAOS is a major challenge in contemporary materials design, as evidenced by a wide array of experimental ${ }^{5-8}$ and theoretical ${ }^{9-12}$ studies on the topic.

The issue of conductivity is related to the fact that the VBM in most oxide materials comprised $O 2 p$ orbitals. Oxygen is a relatively small atom with a high electronegativity, and the result is that the valence band is typically localised (in real space), flat (in reciprocal space), and narrow in band width. ${ }^{9,13}$ These properties result in hole localisation and hence high hole effective masses. ${ }^{9,14}$ One strategy that has proved successful in crystalline p-type oxides is to employ metal cations with electronic orbitals at similar energy to oxygen $2 p$ states. The resulting hybridisation widens the valence band and causes hole delocalisation. ${ }^{13-15}$

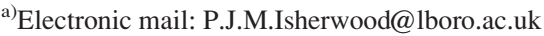

Owing to a reduced hole effective mass, mobility increases along with the conductivity of the material. ${ }^{14}$ Copper (both $\mathrm{Cu}^{+}$and $\mathrm{Cu}^{2+}$ ) and tin (particularly $\mathrm{Sn}^{2+}$ ) are among the cheapest and most widely available metals for this purpose..$^{9,14,16}$

The binary copper oxides $\mathrm{Cu}_{2} \mathrm{O}$ and $\mathrm{CuO}$ are two of the most studied p-type metal oxides. ${ }^{17-19} \mathrm{Cu}_{2} \mathrm{O}$ was one of the first materials found to exhibit the photovoltaic effect, and was being investigated for use in photovoltaics prior to $\mathrm{Si}^{20,21}$ As p-type transparent conducting oxides (TCOs), neither are ideal. TCOs should have an optical band gap of $3 \mathrm{eV}$ or more, thereby ensuring reasonable transmission of the visible spectrum. ${ }^{13,15}$ The band gaps of both copper oxides are too small. ${ }^{13,16}$ Other examples of p-type oxides include $\mathrm{SnO}, \mathrm{NiO}, \mathrm{Cr}_{2} \mathrm{O}_{3}$, and $\mathrm{CuAlO}_{2}{ }^{16,22-24}$ The development of p-type oxides with robust conductivity and appropriate band gaps for TCO applications remains a challenge.

The technique of alloying two highly mismatched materials has been shown to enable tailoring of the band gap of the resulting substance, and has been successfully employed in the III-V semiconductors, such as (In,Ga)As or Ga(As,N). ${ }^{25-27}$ Amorphous materials provide several benefits when compared to crystalline materials. Due to the lack of long-range order, they are typically more flexible and so can be used with a wider range of substrates. ${ }^{28}$ They are also commonly deposited at lower temperatures since heat is not required to encourage the formation of a crystal lattice. ${ }^{15,28}$ Forming an amorphous material from highly mismatched materials ensures a large kinetic barrier for recrystallisation and hence a more robust disordered state.

In this study, we explore the formation of a ternary oxide mixture of $\mathrm{Cu}$ and $\mathrm{Sn}$. Due to the mismatch between the crystal structures of $\mathrm{CuO}, \mathrm{Cu}_{2} \mathrm{O}, \mathrm{SnO}$, and $\mathrm{SnO}_{2}$, an amorphous ternary oxide is formed. The distinct electron configurations of the two cations- $\mathrm{Cu}(\mathrm{II})$ is $3 \mathrm{~d}^{9}$, whilst $\mathrm{Sn}$ (II) is 
$5 s^{2}$-allows us to investigate the effects of altering the composition on the position and structure of the band edge, both of which are critical for designing p-type TAOS. We identify a "compositional mobility edge," where a sharp change in the conductivity and transparency of the material is observed with a small change in $\mathrm{Cu}: \mathrm{Sn}$ ratio, despite the gradual change in the band gap. This finding is explained by comparison with density functional theory (DFT) calculations of the evolution of the electronic density of states (DOS) with composition. The ability to affect gradual change in certain material properties whilst causing much more rapid alteration in others through the application of mismatched alloying is an important principle for designing p-type TAOS.

\section{METHODOLOGY}

\section{A. Experimental}

Thin-film deposition was carried out using an AJA International Orion $8 \mathrm{HV}$ sputter coater equipped with an AJA 600 series radio frequency (RF) power supply and an Advanced Energy MDX 500 DC power supply. Films were deposited by co-sputtering from pre-formed ceramic metal oxide targets at a pressure of $1 \mathrm{mTorr}(0.133 \mathrm{~Pa})$ in a mixed oxygen-argon atmosphere. Film composition was varied by altering the power supplied to each deposition magnetron, thereby varying the deposition rate for the target material. $\mathrm{SnO}_{2}$ was deposited using the DC power supply, and applied power was varied from $12.5 \mathrm{~W}$ to $50 \mathrm{~W}$. $\mathrm{CuO}$ was deposited using the RF power supply, and applied power was varied from $72 \mathrm{~W}$ to $180 \mathrm{~W}$. Argon flow rate was maintained at 7 standard cubic centimetres per minute (SCCM). Two sets of films were deposited, one with a pure oxygen flow rate of 1 SCCM and a second with an oxygen flow rate of 2 SCCM, resulting in oxygen partial pressures of $0.017 \mathrm{~Pa}$ and $0.03 \mathrm{~Pa}$, respectively.

Film characterisation involved measurement of transmission, film thickness, sheet resistance and Hall mobility, compositional and crystal structure analysis, and detailed observation of both film surfaces and in cross-section using SEM and TEM. Transmission data were used to calculate the film band gap using the Tauc method. ${ }^{29}$ Transmission was measured using a Cary Varian 5000 spectrophotometer. Thickness was measured using an Ambios XP2 stylus profilometer, and Hall mobility measurements were carried out using an Ecopia HMS 3000 Hall effect device. Carrier type was confirmed by exploiting the Seebeck effect and measuring the output Voltage. A four-point probe was used to measure sheet resistance, and these data were used to verify the resistivities measured using the Hall effect. Crystal structure was examined using X-ray diffraction (XRD) using a Brucker D2 Phaser benchtop diffractometer equipped with a $\mathrm{Cu}-\mathrm{K}_{\alpha} \mathrm{X}$-ray gun and a Lynxeye ${ }^{\mathrm{TM}}$ detector. The beam slit was $1 \mathrm{~mm}$ wide, and the antiscatter plate was positioned $3 \mathrm{~mm}$ above the sample. SEM was carried out using a Carl Zeiss Leo $1530 \mathrm{VP}$ field emission gun scanning electron microscope. Aperture size was $30 \mu \mathrm{m}$ and the operating voltage was $5 \mathrm{kV}$. TEM was conducted using a FEI Tecnai F20 field emission gun transmission electron microscope equipped with a bright field detector at an operating voltage of $200 \mathrm{kV}$. TEM samples were prepared by focused ion beam milling using a dual beam FEI Nova 600 Nanolab scanning electron microscope. A standard in-situ lift-out method was used to prepare cross-sectional samples. A thin platinum cover layer was deposited to define the sample surface and to homogenize the final sample thinning. Samples were thinned to $75 \mathrm{~nm}$. Compositional analysis was carried out using a Thermo Scientific K-Alpha ${ }^{\mathrm{TM}} \mathrm{X}$-ray photoelectron spectrometer equipped with a monochromated $\mathrm{Al}-\mathrm{K}_{\alpha} \mathrm{X}$-ray gun $(h v=1486.6 \mathrm{eV})$, an EX06 ion source, and a $180^{\circ}$ double focusing hemispherical 128 channel analyser. Measurements were run at a base pressure of $3 \times 10^{-7} \mathrm{mBar}$. The survey scan range was 0 to $1350 \mathrm{eV}$ with a pass energy of $200 \mathrm{eV}$. Step size was $1 \mathrm{eV}$, and data were collected over 10 scans, with $10 \mathrm{~ms}$ dwell time per step. High-resolution scans were run with a pass energy of $50 \mathrm{eV}$. Step size was $0.1 \mathrm{eV}$, and data were collected over five scans with $50 \mathrm{~ms}$ dwell time per step. Samples were subjected to a $75 \mathrm{~s}$ low power $\mathrm{Ar}+$ etch ( $200 \mathrm{eV}$ beam energy) prior to measurement so as to remove any adventitious surface contamination. Peaks were identified and fitted using the Thermo Advantage analysis suite, using Smart (a Shirley variant) background subtraction.

\section{B. Computational}

All DFT calculations were performed within periodic boundary conditions using the Vienna $A b$ Initio Simulation Package $(\mathrm{VASP})^{30}$ and the projector augmented wave formalism. ${ }^{31,32}$ To represent the electron density, a plane wave basis with a kinetic cut-off energy of $500 \mathrm{eV}$ was used. We employed the PBESol and HSE06 exchange and correlation functionals. ${ }^{33,34}$

Amorphous structures were obtained by following the "melt and quench" scheme using ab initio molecular dynamics. The starting point was a random configuration with a stoichiometry chosen to match the experimentally determined atomic composition ${ }^{35}$ in a simulation cell set to a volume obtained by interpolation between the volumes of the respective binary phases. The atoms in the random configuration were packed according to cut-off ratios to avoid spurious interactions and their positions were determined by the RandomGenerator package. ${ }^{36}$ The simulations were then run for $20 \mathrm{ps}$ at $3000 \mathrm{~K}$, with a timestep of $2 \mathrm{ps}$ and the semilocal PBEsol functional. The resultant configuration was then cooled by a simulated annealing procedure over $60 \mathrm{ps}$ to $0 \mathrm{~K}$. At $0 \mathrm{~K}$, the structure was locally optimised with respect to both ionic positions and cell volume. Finally, the electronic structure of the systems obtained was calculated using the screened non-local HSE06 hybrid functional. ${ }^{34}$ The importance of an accurate treatment of electron self-interaction (which we achieve by inclusion of Hartree-Fock exchange) has been shown for amorphous oxides. ${ }^{37}$

The resulting amorphous structures are also analysed using the R.I.N.G.S. package ${ }^{38}$ to identify bonding motifs and under-coordinated centers. These are particularly important in amorphous semiconductors as trap states, ${ }^{39-42}$ unlike crystalline materials where point ${ }^{43}$ and extended defects ${ }^{44}$ tend to dominate. 


\section{RESULTS AND DISCUSSION}

\section{A. Structural characteristics}

Analysis of the XRD patterns confirms that all of the mixed oxide films are amorphous, with no peaks present. Several samples were tested over longer timescales with the same result (Figure 1). TEM cross-sections also indicate that these materials are amorphous, with no crystal structure being visible (Figure 1).

SEM analysis showed that the films exhibit a significant number of surface structures and surface topology (Figure 2). Whilst the cause of this is not known, it is possible that it is related to partial phase separation. Films deposited at high temperatures (above $200^{\circ} \mathrm{C}$ ) were found to exhibit large-scale phase separation which was visible without magnification (Figure 2). For the samples studied herein, the separation is minimal.

\section{B. Optical and electronic properties}

It was found that the addition of $\mathrm{CuO}\left(E_{g}=1.2 \mathrm{eV}\right)$ to $\mathrm{SnO}_{2}\left(E_{g}=3.6 \mathrm{eV}\right)$ caused a significant reduction in the band gap of the resulting material. The shift in band gap with increasing copper content was found to be non-linear (Figure 3 ). The addition of more oxygen to the deposition environment was found to have no significant impact.

The change in band gap of an alloy can usually be described by a quadratic bowing parameter, following:

$$
E_{g}\left(A_{x} C_{1-x}\right)=x E_{g}(A)+(1-x) E_{g}(C)-b x(1-x),
$$
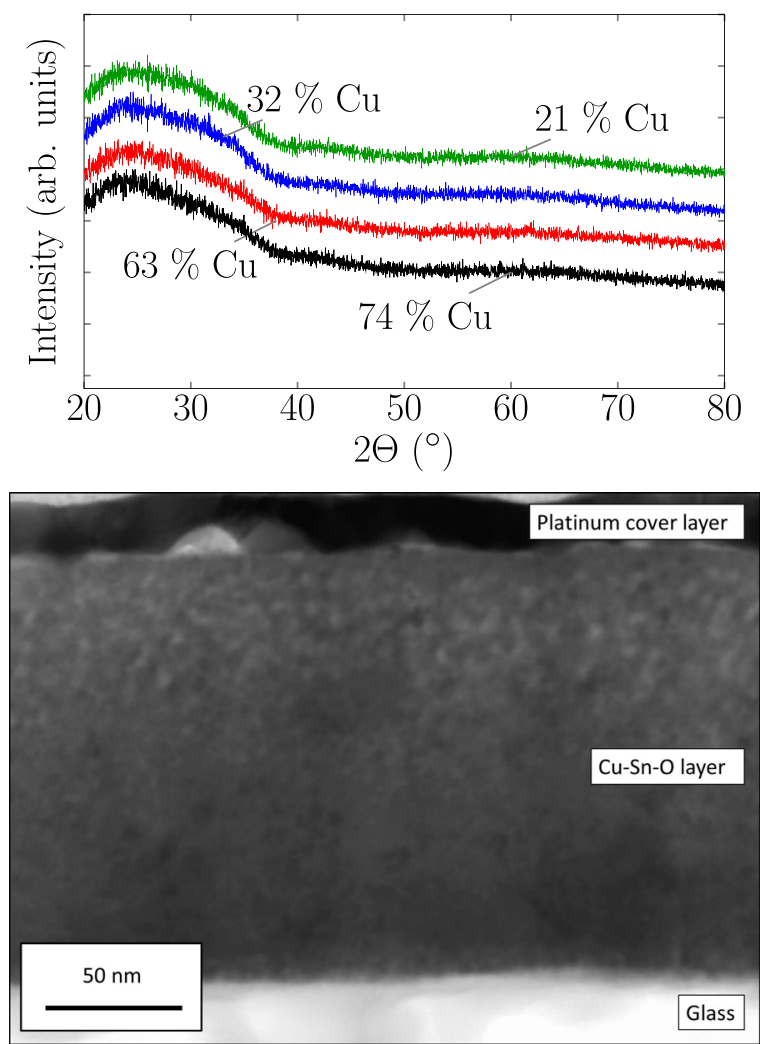

FIG. 1. (Upper) XRD patterns for thin-films with varying copper content. (Lower) TEM image of a $\mathrm{Cu}-\mathrm{Sn}-\mathrm{O}$ alloy film.

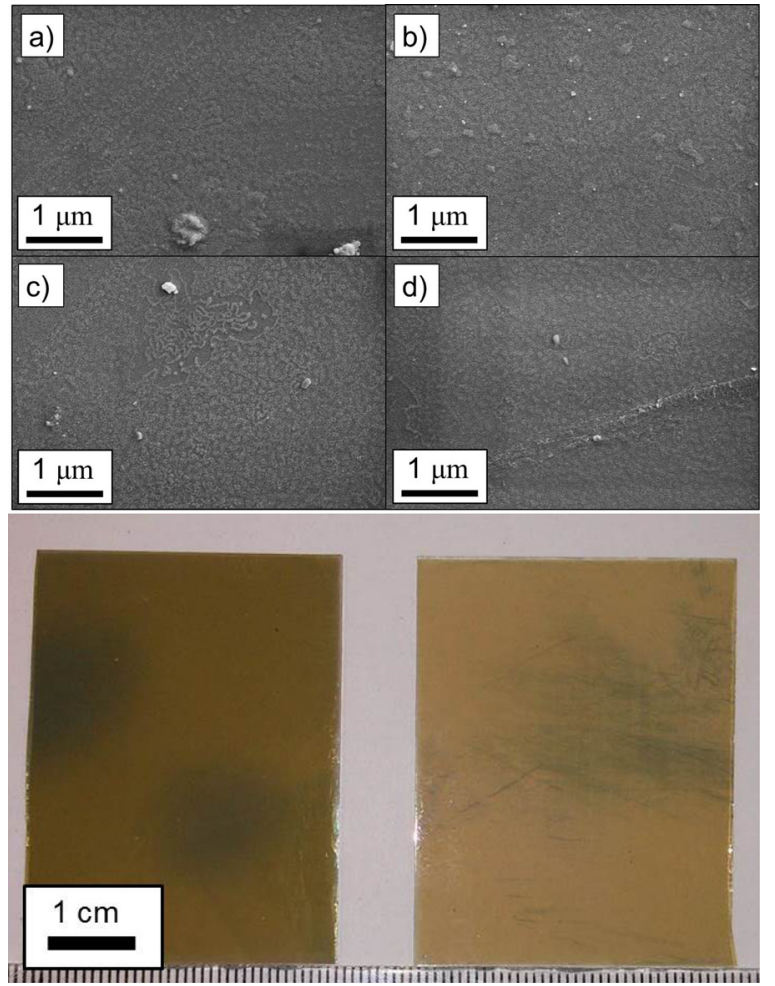

FIG. 2. (Upper) SEM photomicrographs of mixed copper tin oxide films. Films have copper contents of $74 \%$ (a), 63\% (b), 32\% (c), and $21 \%$ (d). (Lower) Films deposited at $300{ }^{\circ} \mathrm{C}$ showing discolouration indicative of large-scale phase separation.

where $E_{g}(A)$ and $E_{g}(C)$ are the band gaps of the two endmember compounds, $x$ is the proportion of semiconductor $A$ that is present in the alloy, and $b$ is the bowing parameter. It was not possible to find a successful fit to measured data using the binary oxides as end member materials. By instead extrapolating the curve to the axes at either end of the sequence, it was possible to extract a compositionally independent bowing parameter of $-1.5 \mathrm{eV}$. This large bowing is consistent with the mismatch between the charge state and

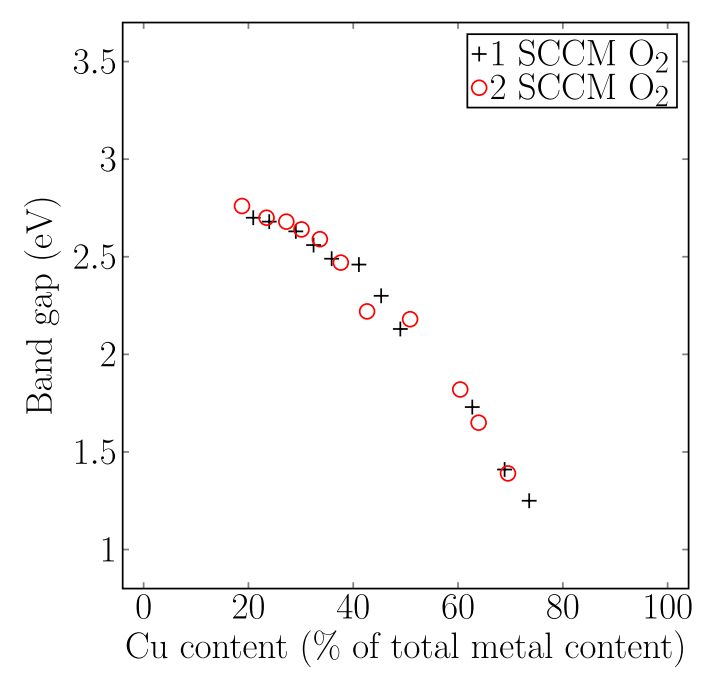

FIG. 3. Optical band gap against film copper content (as a percentage of total metal content) for both oxygen deposition environments. 
structural preferences of $\mathrm{Cu}$ and $\mathrm{Sn}$, and is typical of the values observed in other mismatched alloys. ${ }^{45,46}$

Contrary to the bandgap trends, the averaged optical transmissions for each film did not show the same smooth change across the composition range. Instead, there is a gradual decline in transmission with increasing copper content up to a critical value of around $50 \%$ of the total metal content, beyond which the transmission drops rapidly (Figure 4). Low energy optical transitions can be associated with $\mathrm{Cu}(\mathrm{II})$ $3 \mathrm{~d}^{9}$ centres.

Electrical resistivity was found to mirror the change shown by average transmission. Resistivity is roughly constant with increasing copper content up to the same critical point of around $50 \%$ of the total metal content, with further increases causing an exponential reduction in the resistivity (Figure 4). Unfortunately, it was not possible to obtain reliable carrier concentration and mobility data due to the limitations of the Hall system when measuring low mobility materials. Seebeck tests confirmed that all films showed p-type electrical behaviour.

\section{Materials modelling}

Pair correlation functions (PCFs) of the various samples show that the average $\mathrm{Cu}-\mathrm{O}$ bond length is $2.5 \AA$, whereas the average for $\mathrm{Sn}-\mathrm{O}$ bonds is $2.8 \AA$. By integrating over the first peak of the PCFs, we are able to obtain the average coordination number of various species present. This analysis shows that increasing $\mathrm{Cu}$ content generally leads to increased oxygen coordination. Under-coordinated species in amorphous semiconductors have been shown to be the cause of sub-gap states ${ }^{39,47}$ and are also detrimental to charge carrier lifetimes, ${ }^{41}$ therefore the enhanced coordination in $\mathrm{Cu}$
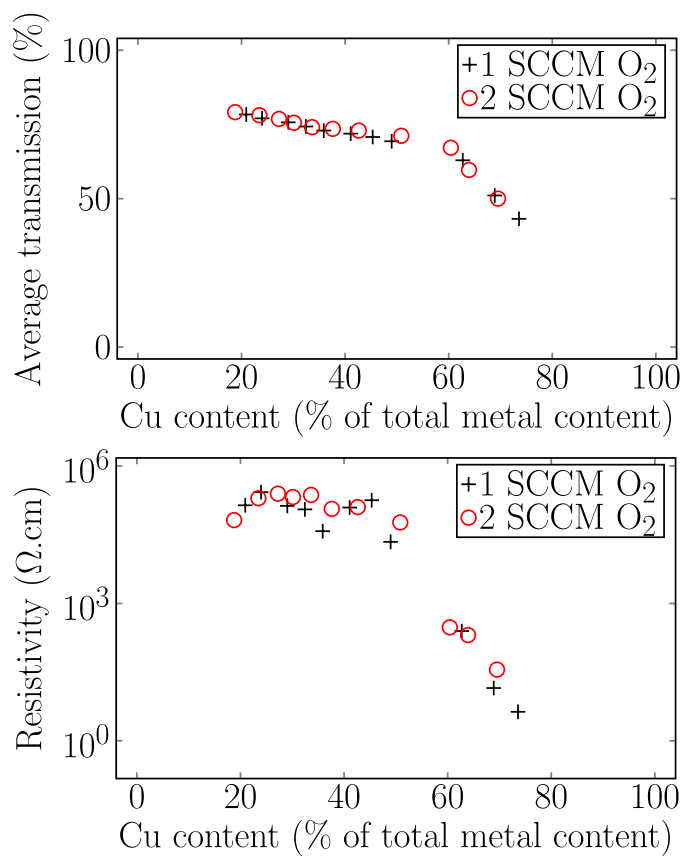

FIG. 4. (Upper) Average optical transmission against copper content (as a percentage of total metal content). (Lower) Film resistivity against film copper content. rich samples should lead to decreased oxygen related subgap states.

The species resolved density of states (PDOS) is shown in Figure 5, which demonstrates the distinct electronic structure of the samples in $\mathrm{Cu}$-rich and $\mathrm{Sn}$-rich regions. The upper valence states become dominated by $\mathrm{Cu} 3 \mathrm{~d}$ character in the $\mathrm{Cu}$ rich region as also confirmed in the electron density plots. In the Cu-rich samples, the edge of the density of states is steeper; however, there are noticeable gap states indicative of the empty d band of $\mathrm{Cu}(\mathrm{II})$. The presence of these gap states is consistent with the sharp change in rate of decrease in the transmission when $\mathrm{Cu}$ content is over $50 \%$, with no equivalent change in bandgap. Sample absorption curves ${ }^{35}$ have been shown to indicate the existence of sub-gap states. ${ }^{48}$ For conclusive experimental evidence, the use of hard X-ray XPS would be necessary; however, this is beyond the scope of the current study.

To further understand the abrupt change in conductivity, when the $\mathrm{Cu}$ content is greater than $50 \%$, we have further analysed the simulated amorphous phases in terms of disorder and fluctuations in the local Madelung potential (which largely determines the carrier energies in oxide systems $\left.{ }^{49}\right)$ disorder. The site Madelung potential $\left(V_{M}\right)$ is calculated by integrating the Hartree potential $\left(V_{H}\right)$ over the ionic site

$$
V_{M}=\int_{V} V_{H} d r
$$
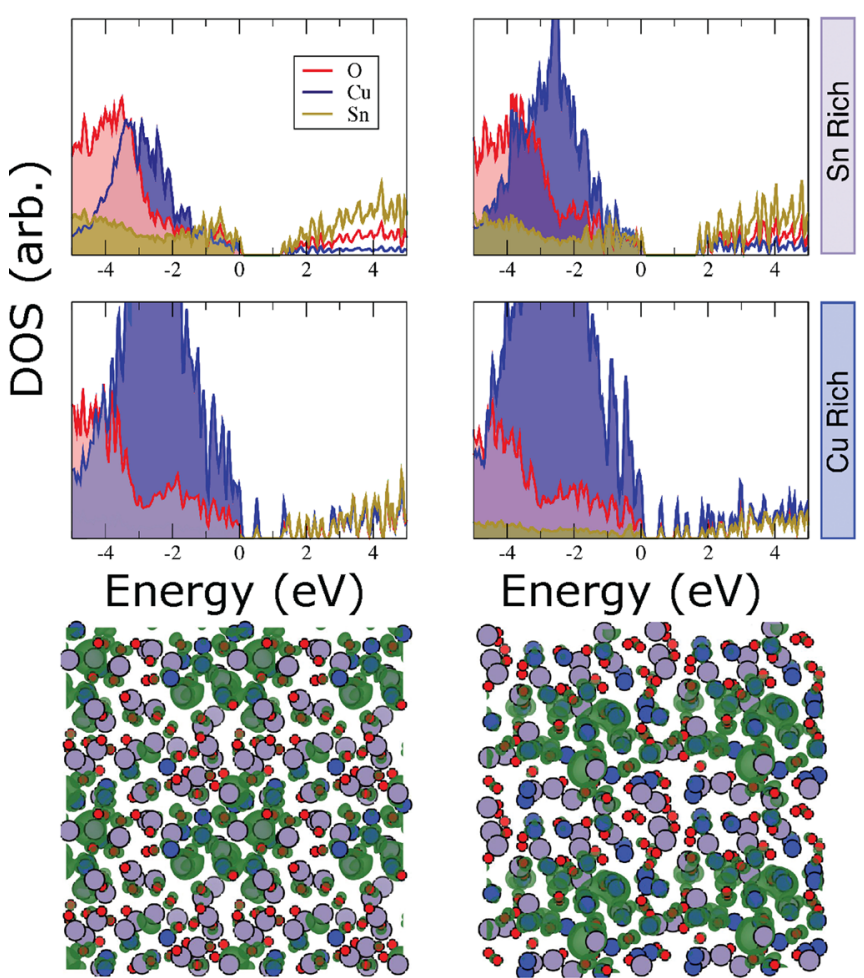

FIG. 5. (Upper) Electronic density of states and (lower) real space electronic distribution of the upper valence band of a $\mathrm{Cu}$-rich and $\mathrm{Sn}$-rich alloys. The stoichiometries of the samples for the DOS are for the Sn rich samples 20:74:105 (left) and 16:33:52 (right), and for the $\mathrm{Cu}$ rich sample 33:20:49 (left) and 74:20:105 (right). The density isosurface is plotted at $1 \times 10^{-3} \mathrm{e}^{-3} \cdot \mathrm{Cu}$ atoms are blue, $\mathrm{Sn}$ atoms are grey, and $\mathrm{O}$ atoms are red. 
TABLE I. Results from DFT simulations showing the $x: y: z$ is stoichiometry in $\mathrm{Cu}_{x} \mathrm{Sn}_{y} \mathrm{O}_{z}$, the average metal to oxygen separation in $\AA$ (where $\mathrm{M}$ is the dominant metal cation), the average oxygen coordination number $\left(\left\langle O_{c n}\right\rangle\right)$, the dominant metal contribution to the valence band maximum (VBM), and the standard deviation in the site Madelung potentials $\left(\Delta V_{C u}\right.$ and $\Delta V_{S n}$ in $\mathrm{V}$ ).

\begin{tabular}{lccccc}
\hline \hline x:y:z & $d(\mathrm{M}-\mathrm{O})$ & $\left\langle O_{c n}\right\rangle$ & $\mathrm{VBM}$ & $\Delta V_{C u}$ & $\Delta V_{S n}$ \\
\hline 20:74:105 & 2.8 & 3.42 & $\mathrm{Sn}$ & 0.4 & 1.0 \\
16:33:52 & 2.8 & 3.36 & $\mathrm{Sn}$ & 0.4 & 1.0 \\
33:20:49 & 2.5 & 3.54 & $\mathrm{Cu}$ & 0.3 & 0.9 \\
74:20:105 & 2.5 & 3.67 & $\mathrm{Cu}$ & 0.6 & 0.9 \\
\hline \hline
\end{tabular}

which we perform using the MacroDensity package. ${ }^{50}$ This allows us to obtain the variation in the Madelung potential resolved by atomic site, as presented in Table I.

The p-type conductivity will relate to the cationic sites that define the top of the valence band, i.e., the $\mathrm{Cu}$ sites in $\mathrm{Cu}$ rich samples. Following the Anderson localisation model, if there is energetic disorder across these sites, then only a fraction is deemed "favourable" for conduction. Conduction is said not to occur if the difference in potential between sites exceeds $\gamma V$. If the spread of the disorder is defined as $W$, then the fraction of sites participating in conduction pathways is ${ }^{51}$

$$
p \approx \frac{2 \gamma V}{W}
$$

There will be a percolation problem and the hole will become localised if $p$ is less than a certain threshold.

For the copper tin oxides studied here, the variance in the Sn site Madelung potential is most pronounced and a spread in potential of $\approx 1 \mathrm{~V}$ will lead to poor conductivity (see Table I). The variance in the $\mathrm{Cu}$ site potential is almost half that of $\mathrm{Sn}(\approx 0.5 \mathrm{~V})$. Therefore, the mobility edge of the alloy can be controlled with composition.

The concept of a compositional mobility edge explains the unusual simultaneous decrease in resistivity and optical transmission. At the same point where the band edge becomes dominated by $\mathrm{Cu}$ states, which offer a percolation path through the material for holes, the sub gap states associated with unfilled $\mathrm{Cu}$ orbitals also appear. If the sub-gap $\mathrm{Cu}$ d-bands are key to obtaining a low film resistivity, ${ }^{52}$ then it is extremely unlikely that a p-type $\mathrm{Cu}$ (II) oxide based material could be synthesised which is simultaneously optically transparent and semiconducting. However, the principles outlined here suggest further routes for the development of ternary (and higher order) conductive p-type amorphous materials. In particular, the existence of compositional edges for some properties (conductivity) and not for others (bandgap) demonstrates the ability to independently control such key physical properties.

\section{CONCLUSIONS}

From a combined experimental and computational study of ternary $\mathrm{Cu}-\mathrm{Sn}$ oxides, all alloy compositions were found to be amorphous. The optical band gap was found to decrease gradually with increasing copper content, and a bowing parameter of $-1.5 \mathrm{eV}$ was calculated. In contrast, both optical transmission and electrical resistivity were found to show little change at lower $\mathrm{Cu}$ content. There is a sharp transition as the $\mathrm{Cu}$ content reaches $50 \%$, with further increases causing dramatic reductions in both resistivity and transmission. Simulations of the amorphous phases from first-principles indicate that this transition occurs at the point where the metal ion defining the valence band edge switches from $\mathrm{Sn}$ to $\mathrm{Cu}$. This results in reduced energetic disorder and an increase in the number of charge percolation pathways, a "compositional mobility edge." Due to the reduction in optical transmission associated with unfilled $\mathrm{Cu} \mathrm{d}$ bands forming sub-gap states, $\mathrm{Cu}$ (II)-based amorphous oxide alloys of this type are unlikely to be good candidates as amorphous transparent conducting oxides.

\section{ACKNOWLEDGMENTS}

The authors are grateful to RCUK for financial support through the SuperSolar Hub (EPSRC Grant No. EP/J017361/ 1). P.J.M.I. would like to acknowledge the invaluable help and support of Ali Abbas with structural characterisation. The research at Bath has been supported by the EPSRC (Grant Nos. EP/K016288/1 and EP/M009580/1). This work benefited from access to both the University of Bath's High Performance Computing Facility and ARCHER, the UK's national high-performance computing service, which is funded by the Office of Science and Technology through EPSRC's High End Computing Programme (Grant No. EP/ L000202).

${ }^{1}$ E. Fortunato, P. Barquinha, and R. Martins, Adv. Mater. 24, 2945 (2012). ${ }^{2}$ V. Pecunia, K. Banger, and H. Sirringhaus, Adv. Electron. Mater. 1, 1400024 (2015)

${ }^{3}$ Y.-H. Kim, J.-S. Heo, T.-H. Kim, S. Park, M.-H. Yoon, J. Kim, M. S. Oh, G.-R. Yi, Y.-Y. Noh, and S. K. Park, Nature 489, 128 (2012).

${ }^{4}$ J. F. Wager, Science 300, 1245 (2003).

${ }^{5}$ N. Masó and A. R. West, Chem. Mater. 24, 2127 (2012).

${ }^{6}$ U. A. Joshi and P. A. Maggard, J. Phys. Chem. Lett. 3, 1577 (2012).

${ }^{7}$ A. J. Leenheer, J. D. Perkins, M. F. A. M. van Hest, J. J. Berry, R. P. O’Hayre, and D. S. Ginley, Phys. Rev. B 77, 115215 (2008).

${ }^{8}$ J. Robertson and Y. Guo, Appl. Phys. Lett. 104, 162102 (2014).

${ }^{9}$ G. Hautier, A. Miglio, G. Ceder, G.-M. Rignanese, and X. Gonze, Nat. Commun. 4, 2292 (2013).

${ }^{10}$ J. B. Varley, V. Lordi, A. Miglio, and G. Hautier, Phys. Rev. B 90, 045205 (2014).

${ }^{11}$ H. Peng, A. Zakutayev, S. Lany, T. R. Paudel, M. D’Avezac, P. F. Ndione, J. D. Perkins, D. S. Ginley, A. R. Nagaraja, N. H. Perry, T. O. Mason, and A. Zunger, Adv. Funct. Mater. 23, 5267 (2013).

${ }^{12}$ D. O. Scanlon, K. G. Godinho, B. J. Morgan, and G. W. Watson, J. Chem. Phys. 132, 024707 (2010).

${ }^{13}$ H. Yanagi, S.-I. Inoue, K. Ueda, H. Kawazoe, H. Hosono, and N. Hamada, J. Appl. Phys. 88, 4159 (2000).

${ }^{14}$ A. Kudo, H. Yanagi, H. Hosono, and H. Kawazoe, Appl. Phys. Lett. 73, 220 (1998).

${ }^{15}$ Handbook of Transparent Conductors, edited by D. S. Ginley, H. Hosono, and D. C. Paine (Springer, London, 2010).

${ }^{16}$ J. A. Caraveo-Frescas, P. K. Nayak, H. A. Al-Jawhari, D. B. Granato, U. Schwingenschlögl, and H. N. Alshareef, ACS Nano 7, 5160 (2013).

${ }^{17}$ J. W. Hodby, T. E. Jenkins, C. Schwab, H. Tamura, and D. Trivich, J. Phys. C: Solid State Phys. 9, 1429 (1976).

${ }^{18}$ D. Scanlon, B. Morgan, G. Watson, and A. Walsh, Phys. Rev. Lett. 103, 096405 (2009).

${ }^{19}$ T. Sander, C. T. Reindl, M. Giar, B. Eifert, M. Heinemann, C. Heiliger, and P. J. Klar, Phys. Rev. B 90, 045203 (2014).

${ }^{20}$ N. F. Mott, Proc. R. Soc. London, Ser. A 171, 281 (1939).

${ }^{21}$ A. W. Copeland, O. D. Black, and A. B. Garrett, Chem. Rev. 31, 177 (1942). 
${ }^{22}$ H. Kawazoe, M. Yasukawa, H. Hyodo, M. Kurita, H. Yanagi, and H. Hosono, Nature 389, 939 (1997).

${ }^{23}$ H. Sato, T. Minami, S. Takata, and Y. Yamada, Thin Solid Films 236, 27 (1993).

${ }^{24}$ E. Arca, K. Fleischer, and I. V. Shvets, Appl. Phys. Lett. 99, 111910 (2011).

${ }^{25}$ T. S. Kim, T. V. Cuong, C. S. Park, J. Y. Park, H. J. Lee, E. Suh, and C. Hong, J. Korean Phys. Soc. 43, 273 (2003).

${ }^{26}$ S. V. Novikov, C. R. Staddon, A. V. Akimov, R. P. Campion, N. Zainal, A. J. Kent, C. T. Foxon, C. H. Chen, K. M. Yu, and W. Walukiewicz, J. Cryst. Growth 311, 3417 (2009).

${ }^{27}$ C. Caetano, M. Marques, L. G. Ferreira, and L. K. Teles, Appl. Phys. Lett. 94, 241914 (2009).

${ }^{28}$ S. Narushima, H. Mizoguchi, K. I. Shimizu, K. Ueda, H. Ohta, M. Hirano, T. Kamiya, and H. Hosono, Adv. Mater. 15, 1409 (2003).

${ }^{29}$ J. Tauc, Mater. Res. Bull. 3, 37 (1968).

${ }^{30}$ G. Kresse, Phys. Rev. B 54, 11169 (1996).

${ }^{31}$ P. E. Blöchl, Phys. Rev. B 50, 17953 (1994).

${ }^{32}$ G. Kresse, Phys. Rev. B 59, 1758 (1999).

${ }^{33}$ J. P. Perdew, A. Ruzsinszky, G. I. Csonka, O. A. Vydrov, G. E. Scuseria, L. A. Constantin, X. Zhou, and K. Burke, Phys. Rev. Lett. 100, 136406 (2008).

${ }^{34}$ A. V. Krukau, O. A. Vydrov, A. F. Izmaylov, and G. E. Scuseria, J. Chem. Phys. 125, 224106 (2006).

${ }^{35}$ See supplemental material at http://dx.doi.org/10.1063/1.4929752 for further information on stoichiometries and oxidation state data used for model construction, and for representative absorption curves for deposited films.

${ }^{36} \mathrm{See}$ https://github.com/keeeto/AmorphousStructureGenerator for keeeto/ AmorphousStructureGenerator (last accessed August 05, 2013).

${ }^{37}$ W. Körner, D. F. Urban, D. M. Ramo, P. D. Bristowe, and C. Elsässer, Phys. Rev. B 90, 195142 (2014).
${ }^{38}$ S. L. Roux and P. Jund, Comput. Mater. Sci. 49, 70 (2010).

${ }^{39}$ S. Sallis, K. T. Butler, N. F. Quackenbush, D. S. Williams, M. Junda, D. A. Fischer, J. C. Woicik, N. J. Podraza, B. E. White, A. Walsh, and L. F. J. Piper, Appl. Phys. Lett. 104, 232108 (2014).

${ }^{40}$ W. Körner and C. Elsässer, Thin Solid Films 555, 81 (2014).

${ }^{41}$ M. W. Lamers, K. T. Butler, J. H. Harding, and A. Weeber, Sol. Energy Mater. Sol. Cells 106, 17 (2012).

${ }^{42}$ K. T. Butler, M. P. W. E. Lamers, A. W. Weeber, and J. H. Harding, J. Appl. Phys. 110, 124905 (2011)

${ }^{43}$ K. G. Godinho, J. J. Carey, B. J. Morgan, D. O. Scanlon, and G. W. Watson, J. Mater. Chem. 20, 1086 (2010).

${ }^{44}$ S.-H. Yoo, K. T. Butler, A. Soon, A. Abbas, J. M. Walls, and A. Walsh, Appl. Phys. Lett. 105, 062104 (2014).

${ }^{45}$ Y. Z. Zhu, G. D. Chen, H. Ye, A. Walsh, C. Y. Moon, and S. H. Wei, Phys. Rev. B 77, 245209 (2008).

${ }^{46}$ N. Tit, I. M. Obaidat, and H. Alawadhi, J. Phys.: Condens. Matter 21, 075802 (2009).

${ }^{47}$ S. Sallis, N. F. Quackenbush, D. S. Williams, M. Senger, J. C. Woicik, B. E. White, and L. F. J. Piper, Phys. Status Solidi A 212, 1471 (2015).

${ }^{48}$ K. Nomura, T. Kamiya, H. Yanagi, E. Ikenaga, K. Yang, K. Kobayashi, M. Hirano, and H. Hosono, Appl. Phys. Lett. 92, 202117 (2008).

${ }^{49}$ A. Walsh and K. T. Butler, Acc. Chem. Res. 47, 364 (2014).

${ }^{50}$ See https://github.com/WMD-Bath/MacroDensity for WMD-Bath/ MacroDensity (last accessed August 05, 2013).

${ }^{51}$ Models of Disorder: The Theoretical Physics Of Homogeneously Disordered Systems, edited by J. Ziman (Cambridge University Press, Cambridge, 1979).

${ }^{52}$ Y. Peng, Z. Zhang, T. Viet Pham, Y. Zhao, P. Wu, and J. Wang, J. Appl. Phys. 111, 103708 (2012). 